\title{
The Role of Moral Reasoning on the Effects of Incentive Schemes and Working Relationships on Whistleblowing: An Audit Experimental Study
}

\author{
Supriyadi ${ }^{*}$, Nidaul Uswah Prasetyaningsiba \\ ${ }^{a}$ Universitas Gadjah Mada, Indonesia
}

\begin{abstract}
This study examines the role of moral reasoning in strengthening the effects of the working relationship and incentive schemes on the likelihood of reporting accounting fraud. This study predicts that higher moral reasoning, or being exposed to incentive schemes, is more likely to cause someone to be a whistleblower. However, individuals with a close working relationship with wrongdoers will exhibit a lower propensity to blow the whistle than those with no close working relationship. Finally, moral reasoning is expected to interact with working relationships and incentive schemes to affect the propensity to blow the whistle. Based on a lab experiment with 147 participants, this study documents that the simple effect of moral reasoning, the working relationship, or an incentive scheme are (marginally) significant. Similarly, the combination of moral reasoning and the working relationship significantly improves the tendency to blow the whistle. However, the combined effects of moral reasoning vs. the working relationship and moral reasoning vs. the working relationship vs. an incentive scheme are not significant. This paper confirms previous studies which found that moral reasoning significantly alters the whistleblowing intention but that the impact of moral reasoning is not robust for incentive schemes and working relationships. Some limitations should be considered, namely the textual scenarios of the experimental design, working experience, and the omission of personal orientation and the personal cost of reporting.
\end{abstract}

Keywords: moral reasoning, incentive scheme, working relationship, accounting fraud, and whistleblowing

JEL Classification: M410, M420, M480 


\section{Introduction}

Whistleblowing has been a subject of growing interest for scholars and the general public, and even more so when a series of frauds and financial scandals, in both global and local financial services, populate the news (Brooks, 2018, The Jakarta Post, 2018a, The Jakarta Post, 2018b). Markedly since the call from Miceli et al., (2008), studies have investigated whistleblowing in various contexts outside of the U.S., such as in, among others, Indonesia (Latan et al., 2018; Latan et al., 2019a and 2019b), Australia (Fieger and Rice, 2018), New Zealand (Liyanarachchi and Newdick, 2009), Norway (Skivenes and Trygstad, 2010), Germany (Lee et al., 2018), Turkey (Erkmen et al., 2014), and Singapore (Boo et al., 2016).

Among the extant literature that measures the whistleblowing intention, mixed evidence is available; firstly, whether moral development plays a significant role in reporting wrongdoing. Cheng et al., (2019) found the role of moral courage in moderating the relationship between organizational politics and internal whistleblowing intentions. Similarly, Dungan et al., (2019) show that moral reasoning consistently predicts whistleblowing decisions across contexts, but it is not robust to the loyalty concern. Doe et al., (2020) and May-Amy et al., (2020) document the significant main effect of normative beliefs and the combined effect of normative beliefs and reward motivation on the intention to blow the whistle. However, they indicate that the main effect of punishment motivation does not significantly affect whistleblowing intentions.

Furthermore, Latan et al., (2018) and Latan et al., (2019a) provide partial support for the relationships between perceived moral intensity and whistleblowing. They find significant direct effects but insignificant moderating effects. Finally, Pangestu and Rahajeng (2020) find insignificant direct support for the moral intensity to whistleblow.

Secondly, if organizational-level incentive schemes effectively affect the whistleblowing intention. Lee et al., (2018) indicate that the whistleblowing intention of U.S. accountants is lowest in the absence of anti-retaliation protection and monetary rewards, but it is highest for German accountants. Latan et al., (2019b) documented that financial incentives strongly support the internal, external, and anonymous whistleblowing intentions. Furthermore, Andon et al., (2018) found direct support for financial incentives affecting whistleblowing intentions. However, when the wrongdoing is severe, the effect of any financial incentive is weak, and vice versa. Similarly, Rose et al., (2018) indicate a partial relationship between monetary rewards and reporting fraud. The results of their experiment suggest that monetary rewards affect reporting intentions differently, depending upon their compensation structures; the effect is not significant with unrestricted stock compensation but significant with restricted stock compensation. Doe et al., (2020) document that rewards and punishment have no direct effect on whistleblowing. However, the interaction between rewards and moral beliefs significantly supports whistleblowing.

Boo et al., (2016) tested the interaction effects of incentive schemes (carrot, stick, and control groups) and working relationships (close and not close groups) on auditors' willingness to report an audit partner's wrongdoing that impairs the quality of the financial reporting in an experimental setting with 90 auditors. Including the working relationship variable in their test was very im- 
portant since the nature of audit work is very team-based. They found that auditors with reward-based incentive schemes who had close cooperative relationships with wrongdoers were less likely to blow the whistle than auditors who did not have a close cooperative relationship. Conversely, auditors on penalty-based incentive schemes tended to blow the whistle despite the existence of close working relationships.

Furthermore, Boo et al., (2016) identified that close working relationships with wrongdoers significantly reduced the auditor's tendency to report misconduct when there was a reward incentive scheme, but this did not occur for incentive schemes with penalties or no incentives. Reward and penalty incentive schemes can increase auditors' tendencies to blow the whistle when there is no close working relationship; however, a reward scheme is less effective than a penalty scheme when there is a close working relationship. The inconsistent results of the moderating effect of incentive schemes on the auditors' propensity to blow the whistle might indicate a missing variable, an inherent individual factor, namely moral capacity.

Zollo et al., (2017) stated that the traditional rationalist framework of ethical decision-making was challenged by the psychological and managerial literature, emphasizing the importance of the decision-maker's cognitive elements, such as intuition and emotion. Based on a social intuitionist perspective, they identify that intuition and moral reasoning are the ethical decision-making process's antecedents. The ethical decision-making framework is a deliberative process that integrates innate moral intuitive abilities with the moral capacity for justifying ethical decision-making. Individual moral capacity is a person's moral reasoning ability or a person's level of moral maturity, by the ethical values that are believed, the stage of development of the person's moral abilities, and feelings of moral sensitivity (Schwartz, 2016). Also, Schwartz (2016) proposed a model of ethical decision-making by placing moral reasoning as a moderating factor, because its role depends on the circumstances at hand.

This study aims to test whether moral reasoning plays a significant role in strengthening the effects of a working relationship and incentive schemes on the likelihood of reporting accounting fraud. The study extends the model by Boo et al., (2016) by adding the individual character of moral reasoning into the model. Through an experimental study, individuals' propensity to blow the whistle is modeled as being influenced by the level of moral reasoning's development, incentive schemes, and working relationships. This study predicts that individuals with higher moral reasoning, or who are exposed to incentive schemes, are more likely to blow the whistle. However, individuals with a close working relationship with wrongdoers will exhibit a lower propensity to blow the whistle than those with no close working relationship. Finally, the individuals' moral reasoning is expected to interact with working relationships and incentive schemes to affect the likelihood of whistleblowing.

Based on a full factorial $2 \times 3$ experimental design with 147 participants who are graduate students in accounting, this study indicates that the simple effect of moral reasoning or a close working relationship is significant. An incentive scheme is marginally significant for increasing the propensity to blow the whistle. Similarly, the combination of moral reasoning and the working relationship significantly improves the tendency to blow the whistle. These results are con- 
sistent with previous studies, such as by Weber \& McGivern (2010), Boo et al., (2016), Latan et al., (2018), Pope \& Lee (2013), and Brink et al., (2013), among others. However, the combined effects of moral reasoning vs. the working relationship and moral reasoning vs. the working relationship vs. incentive schemes fail to increase the tendency to blow the whistle.

The study's contribution to the audit literature on accounting fraud and whistleblowing is threefold. First, this paper is the first study to test the model of whistleblowing with a single comprehensive model that involves the characteristics of an individual character's moral reasoning, motivation schemes with rewards and punishment, and the nature of team work in auditing. The model captures the essential elements surrounding professional auditors, namely integrity, incentives, and team work. Second, the paper confirms the previous research that moral reasoning significantly alters the whistleblowing intention, as documented by Cheng et al., (2019), Dungan et al., (2019), Doe et al., (2020), May-Amy et al., (2020), Latan et al., (2018), and Latan et al., (2020). Finally, the paper documents that the impact of moral reasoning on the whistleblowing intention is not robust, especially when it involves incentive schemes and working relationships in the joint effects model. Since the "carrot vs. stick" incentives could be interpreted as opposites, they may reduce the negative and moderating effect of the working relationship (Wang et al., 2018 and Trompeter et al., 2014). Another plausible reason is that "carrot" may impede whistleblowing since it can be perceived as harming others for personal gain (Boo et al., 2016). Hence there is a canceling effect between the "carrot" incentive scheme and a close working relationship.
Some limitations should be considered. The first is the textual scenarios of the experimental design may not reflex the complex reality and the social interactions of audit work. Second, some of the participants had no work experience, and finally, the omission of other individual-level attributes, such as personal orientation (Park et al., 2014) and the personal cost of reporting (Latan et al., 2018; Latan et al., 2019b; and Schultz et al., 1993).

The remainder of this paper is as follows. The next part presents the literature review, followed by developing the hypotheses, the experimental method employed, and the results. A discussion, the conclusion, and the limitations of the study end the paper.

\section{Literature Review}

\section{Whistleblowing}

Whistleblowing happens when one or more legitimate members of an organization voluntarily disclose and report a violation or fraud that occurs in that organization, to initiate some corrective action to resolve it (Ceva \& Bocchiola, 2018). Whistleblowers come from within the organization where the facts are reported (Miceli \& Near, 1992). Whistleblowing is a form of prosocial behavior which is generally defined as the act of reporting wrongdoing to benefit others and themselves (Brief and Motowidlo, 1986, Dozier and Miceli, 1985, Miceli and Near, 1985).

In contrast to the simple definition of “doing good" (Ariely et al., 2009), prosocial behavior is a complex, multi-level construct with many motives. They are many drivers for individuals' prosocial conduct, such as empathy (Eisenberg and Miller, 1987), altruism (Batson and Powell, 2003), and self-iden- 
tity in the light of social norms (Bénabou and Tirole, 2006). They have been of interest for organizational researchers who seek to tap into what would affect individuals' intentions to blow the whistle as an act of prosocial behavior, and how its effectiveness can be enhanced (Near and Miceli, 1995; Taylor and Curtis, 2010; Singh, 2011).

Whistleblowers can report violations to the organization's internal parties, such as the whistleblower's direct supervisor, higher management levels, or to the ombudsman's office, as well as to external parties, such as the police or the media (Davis, 1996; Delmas, 2015). However, the true subjective intentions of whistleblowers can vary, ranging from selfish ones, such as to bring down other parties or seek fame, to altruistic ones such as protecting colleagues who are victims, or to express a commitment to positive change from the status quo (Miceli \& Near, 1992).

\section{Moral Reasoning}

The foundational works for the study of moral reasoning were laid by Lawrence Kohlberg (Kohlberg, 1971, Kohlberg \& Hersh, 1977) and later refined by James Rest (Rest et al., 1999). Kohlberg's moral theory is the division of six moral development stages which are nested into three levels. Firstly, individuals at the pre-conventional level interpret moral behavior as being based on "the physical or the hedonistic consequences of action ... or in terms of the power of those who enunciate the rules and labels" (Kohlberg \& Hersh, 1977, p. 54). This level comprises of two stages: Stage 1 with "the punishment-and obedience orientation" and Stage 2 with "the instrumental-relativist orientation."

Secondly, individuals at the conventional level value the family or group's expectations, irrespective of any direct consequences. The conventional level is differentiated into two stages: Stage 3, wherein individuals define good behavior as "pleasing or helping others and is approved by them" (p. 55), and Stage 4 , in which individuals conform in their behavior toward "authority, fixed rules, and the maintenance of social order" (p. 55).

Thirdly, the post-conventional level is characterized by the transcendence of moral values and principles, beyond or apart from the referent groups or persons holding the authority. Similar to the previous levels, this level is also divided into two stages: Stage 5 with an emphasis on "social-contract and legalistic orientation" in which right action is defined in terms of individual rights and standards which have been "agreed upon by the whole society" (p. 55), and Stage 6 which emphasizes "the universal-ethical-principle orientation" in which right action appeals to "logical comprehensiveness, universality, and consistency" (p. 55).

Individuals' moral reasoning levels were initially investigated through extended, even ethnographic, qualitative interviews (Kohlberg, 1971). Weber \& McGivern (2010) developed an instrument to describe moral reasoning in business settings using four moral reasoning inventories corresponding to Kohlberg's six stages. ${ }^{1}$ In particular, stages 1 and 2 are merged into one inventory due to their similarity (as Stage $1 \mid 2$ ), Stage 3, Stage 4 , and then stages 5 and 6 are combined as one inventory (as Stage $5 \mid 6$ ). They found that managers generally converge on Stage 4 and intent to report wrongdoings when presented with ethical workplace dilemmas.

Rest (1979) interpreted Kohlberg's stages by developing a distinct inquiry method, called the Defining Issues Test (DIT), to ${ }^{1}$ See also Weber (1991). 
score the individual's moral reasoning into higher or lower scores. In contrast to Rest, Weber (1991) believed that the moral reasoning stages should be understood in terms of the dominant stage across the six stages rather than a single score. Xu \& Ziegenfuss (2008) build on Rest (1979) and incorporated moral reasoning in their internal auditors' study. They broadly distinguished moral reasoning into "high," "mid," and "low" and found support for the positive relationship between the tendency of whistleblowing and the level of moral reasoning. The result is also supported in other studies, such as Tsui (1996), which compared China and USA contexts, and Liyanarachchi \& Newdick (2009), in New Zealand.

\section{Incentive Schemes}

An incentive theory is one of the main motivation theories, which states that behavior is motivated by the desire to get reinforcement or incentives. Two people can act differently in the same situation, based on the types of incentives available (Silverman et al., 2016). Incentives could get people to engage in a particular kind of behavior and action, but they could also stop people taking any specific actions. Incentives will motivate the individual if he/she views the rewards provided as essential and the targeted results are controllable and realistic.

However, the potential benefits of linking compensation with performance are relatively straightforward and consistent, but some behavioral economists still have doubts (Baker et al., 1998). They still see that many companies refuse to introduce and use bonus-based compensation schemes. They indicate that monetary rewards are counterproductive. Deci (1972) argued that money reduces employee motivation because it re- duces the meaning of the intrinsic reward that employees receive from their job's responsibilities. Similarly, Baker et al., (1998) concluded that getting employees to chase money will do nothing but encourage people to chase money.

Kohn (1988) offered two reasons why merit-based payment systems are not effective. First, incentives can push people to focus narrowly on a task, do it as quickly as possible, and take fewer risks. Second, extrinsic rewards can erode intrinsic interests so that people feel they see themselves as being controlled by gifts. Additionally, while financial incentive schemes conceptually increase productivity, in practice, they cause a significant adverse side effect of lowering employees' morale and productivity. The dealing costs with many of the problems caused by the merit system outweigh the limited benefits to the organization. Among the side effects that often arise are horizontal equity problems and problems associated with imperfect performance measures. Hamner (1975) argued that the performance system reduces motivation because managers systematically mismanage payroll programs for performance.

\section{Working Relationships}

Adkins et al., (1996) indicated that it is vital for companies to provide a work environment that can promote and encourage strong working relationships among employees, especially in situations where employee involvement affects almost every aspect of their job. In certain conditions, it will appear that employees are not loyal to the company, but they are loyal to colleagues with whom they have jointly built emotional bonds. Employees with strong bonds of friendship are more likely to remain loyal to their team, and they will also last longer in the company. 
They will see first-hand that their dedication to the team benefits everyone as a whole.

Werbel \& Johnson (2001) added that satisfaction with the work done provides intrinsic motivation for individual employees. However, employees who work in teams and regularly feel the ups and downs of contributions and performance achievements will prefer their work and even tend to love the company. Hence, companies need to make it easier for their employees to share the things they love about their work and their colleagues, to help build stronger bonds.

On the other hand, friends on the same work team can also serve as part of the control system, which is invaluable when employees are in a difficult situation. This condition allows each employee to leverage and encourage his colleagues' motivation and even caution them when they act incorrectly (Adkins et al., 1996 and Werbel \& Johnson, 2001).

\section{Hypotheses Development}

\section{Moral Reasoning and Whistleblowing Intentions}

Miceli (2004) and Rocha and Kleiner (2005) stated that whistleblowing is a unique phenomenon because employees face a tough choice between prioritizing their loyalty to the company or their moral and social obligations to take the right action along with the potential personal consequences faced when blowing the whistle. In the confusion of facing a moral dilemma, many other conditional factors come into play before an employee decides to report finding fraud. Several studies have shown that employees are afraid to report managers' fraud because they believe that their reports will not be followed up, fear that their reports will not be kept secret (Verschoor, 2005), or fear retaliation (Rocha and Kleiner, 2005). Other studies by Latan et al., (2018), Latan et al., (2019a), and Pangestu and Rahajeng (2020) provide partial support, or no support, for the relationship between moral reasoning and whistleblowing.

The behavioral theory indicates that the characteristics of a person's moral behavior can include a desire to help others, a sense of empathy, or a feeling of guilt toward others (Rest 1983). Furthermore, Rest (1983) stated that moral behavior refers to a moral guideline regulating cooperation between humans, and is related to the distribution and allocation of rights, obligations, and benefits. Many studies in this area have concluded that one of the most important factors influencing an individual's decision to blow the whistle is their moral behavior (Near and Miceli, 2005). Besides, Gundlach et al., (2003) also indicated that moral reasoning and retaliation play an essential role in the whistleblowing process. Specifically, Liyanarachchi \& Newdick (2009) reported that individuals with a higher moral reasoning level were more likely to blow the whistle than individuals with a lower moral reasoning level. This result is supported by Cheng et al., (2019), Dungan et al., (2019), Doe et al., (2020), and May-Amy et al., (2020).

In accounting and auditing, as indicated by Dozier and Miceli (1985), a person's ability to solve problems or interpret ethical dilemmas is influenced by his/her moral reasoning. Several other studies, which analyzed the data from research samples of accountants, auditors, or accounting students, have also shown that the subjects' levels of moral reasoning affect their ability to interpret ethical dilemmas (Arnold and Ponemon, 1991; Chan and Leung, 2006; Uddin and Gillett, 2002). This study concludes that a person's moral reason- 
Gadjah Mada International Journal of Business - September-December, Vol. 23, No. 3, 2021

ing level has a positive effect on his/her ethical behavior. Thus, the following hypothesis is formulated.

$H_{1}$ : The higher that the dominant stage of an individual's moral reasoning is, the more likely hel she is to blow the whistle.

\section{Incentive Schemes, Working Relation- ships, and Whistleblowing Intentions}

Miceli et al., (2008) suggested that whistleblowing is a multi-level concept with various predictors. Furthermore, Alleyne et al., (2013) proposed a holistic model that captures institutional-level moderators such as organizational support and team norms, which moderate individuals' whistleblowing intentions. The model is further implemented by Latan et al., (2018). In their study on public accountants in Indonesia, organizational support and team norms were found to play a partial role in improving the relationship between individual-level antecedents and the intention to blow the whistle. Moreover, $\mathrm{Xu}$ \& Ziegenfuss (2008) compared the effects of cash rewards and continuous employment rewards on the whistleblowing intention. Their findings indicated that reward systems were positively related to whistleblowing and that cash rewards appealed more to individuals with lower levels of moral reasoning.

In contrast to the incentives strongly argued to encourage prosocial behavior (Ariely et al., 2009, Bénabou \& Tirole, 2006), an indepth study by Jackson et al., (2010) of nurses' workplaces shed essential light on how workplace relationships complicate the whistleblowing intention. They found that "ostracism and bullying" as well as the "perceived loss of previously successful relationships" (Jackson et al., 2010, p. 41) were among the costs of having engaged in the act of whis- tleblowing. In Milliken et al., (2003), these social sanctions were reflected as "the fear of being labeled negatively" and the "loss of trust and respect" (p. 1462), which foster silence rather than whistleblowing. Included in this social reputation is the element of trust, which is established with one's supervisor.

When group-based work structures occur many times in companies, employee interactions with co-workers become more intense. Companies will support employees who are compatible with each other within the group because the quality of their interactions can improve group performance (Adkins et al., 1996 and Werbel \& Johnson, 2001). This good relationship between co-workers will affect a person's intention to blow the whistle in the event of an ethical violation or illegal activity.

Chang et al., (2017), Rehg et al., (2008), and Cortina \& Magley (2003) showed that good relations between colleagues could have a different impact on the intention to retaliate. When someone has a good relationship with their co-workers, there is a tendency that they will not criticize each other. In line with this concept, it logically makes sense that a close working relationship between employees can reduce the risk perceptions of ethical violations or illegal acts, and subsequently reduce their potential to blow the whistle (Wang et al., 2018).

Acknowledging both the incentives and workplace relationships, a study by Boo et al., (2016) examined the combined effect of incentive systems, in terms of the incentive (or "carrot") and disincentive (or "stick"), and working relationships, in terms of "close" and "not close" relationships with a supervisor. The study found that, while incentive systems increased auditors' likelihood of blowing the whistle, having close working 
relationships weakened the incentives' effectiveness. Accordingly, $\mathrm{H}_{2}$ is formulated to capture these features.

\section{$\mathrm{H}_{2}$ : Individuals exposed to a close working relation-} ship will exbibit a lower likelihood of blowing the whistle than those with no close working relationship.

Many studies in the last decade have tested the positive impact of incentive mechanisms on whistleblowing (Pope \& Lee 2013; Brink et al., 2013; and Xu \& Ziegenfuss 2008). Pope \& Lee (2013), based on experimental data, documented that financial rewards equal to a certain proportion of employees' salaries can encourage their intention to report superiors who deliberately manipulate financial statements. Meanwhile, Brink et al., (2013) also indicated that an internal financial incentive scheme could increase employees' intentions to disclose fraud allegations to authorities outside the company, based upon the existing evidence of fraud. However, employees' tendencies to disclose fraud within the company are still higher than the tendency to disclose it to authorities outside the company. In the realm of internal auditors, $\mathrm{Xu}$ and Ziegenfuss (2008) proved that internal auditors have a greater tendency to disclose mistakes to their superiors when there are financial and non-financial incentives. Similar results are found by Latan et al., (2019b) and Andon et al., (2018).

On the other hand, the threat of punishment schemes did not cause many researchers to carry out tests and analyses, especially about the intention to do whistleblowing. It may occur because whistleblowing interacts more with motivational aspects to modify and change employee behavior, which contradicts the negative sanction scheme (Cortina \& Magley, 2003). However, Arvey \& Ivancevich (1980) indicated that although punishment schemes have unpleasant connotations, punitive sanctions are a common phenomenon in organizations and are adequate to mitigate or eliminate unwanted behavior. More than that, Trompeter et al., (2014) also suggested that punishment schemes can increase the effectiveness of fraud detection measures such as whistleblowing. Accordingly, $\mathrm{H}_{3}$ is formulated to capture these features.

\section{$H_{3}$ : Individuals exposed to reward incentive schemes will show a higher probability of blowing the whistle than those not exposed to such incentive schemes.}

\section{Joint Effect Hypothesis}

A recent study on public accountants in Barbados by Alleyne et al., (2018) found that, while the individual-level characteristics are the main drivers for individuals' intentions to blow the whistle, organizational-level support acts as a catalyst that amplifies the effect. This finding echoes earlier research by Mesmer-Magnus and Viswesvaran (2005) in their meta-analysis on whistleblowing. They found that the organizational climate was strongly related to the whistleblowing intention.

Thus, there are two strands to the argument. On the one hand, individuals with higher moral reasoning (Stage $5 \mid 6$ ) tend to be indifferent toward incentives and working relationships. On the other hand, an organizational climate that includes workplace relationships and incentive systems is argued to act as an amplifier for individual characteristics such as moral reasoning. Hence, the following hypothesis is proposed.

\footnotetext{
$\mathrm{H}_{4}$ : Individuals with a higher moral reasoning stage will find their likelihood of blowing the whistle less affected by working relationships and incentive schemes.
} 
Gadjah Mada International Journal of Business - September-December, Vol. 23, No. 3, 2021

Figure 1 illustrates the relative positioning between moral reasoning, incentive schemes, and working relationships.

\section{Participants}

The participants used for this study were graduate accounting students. In particular,

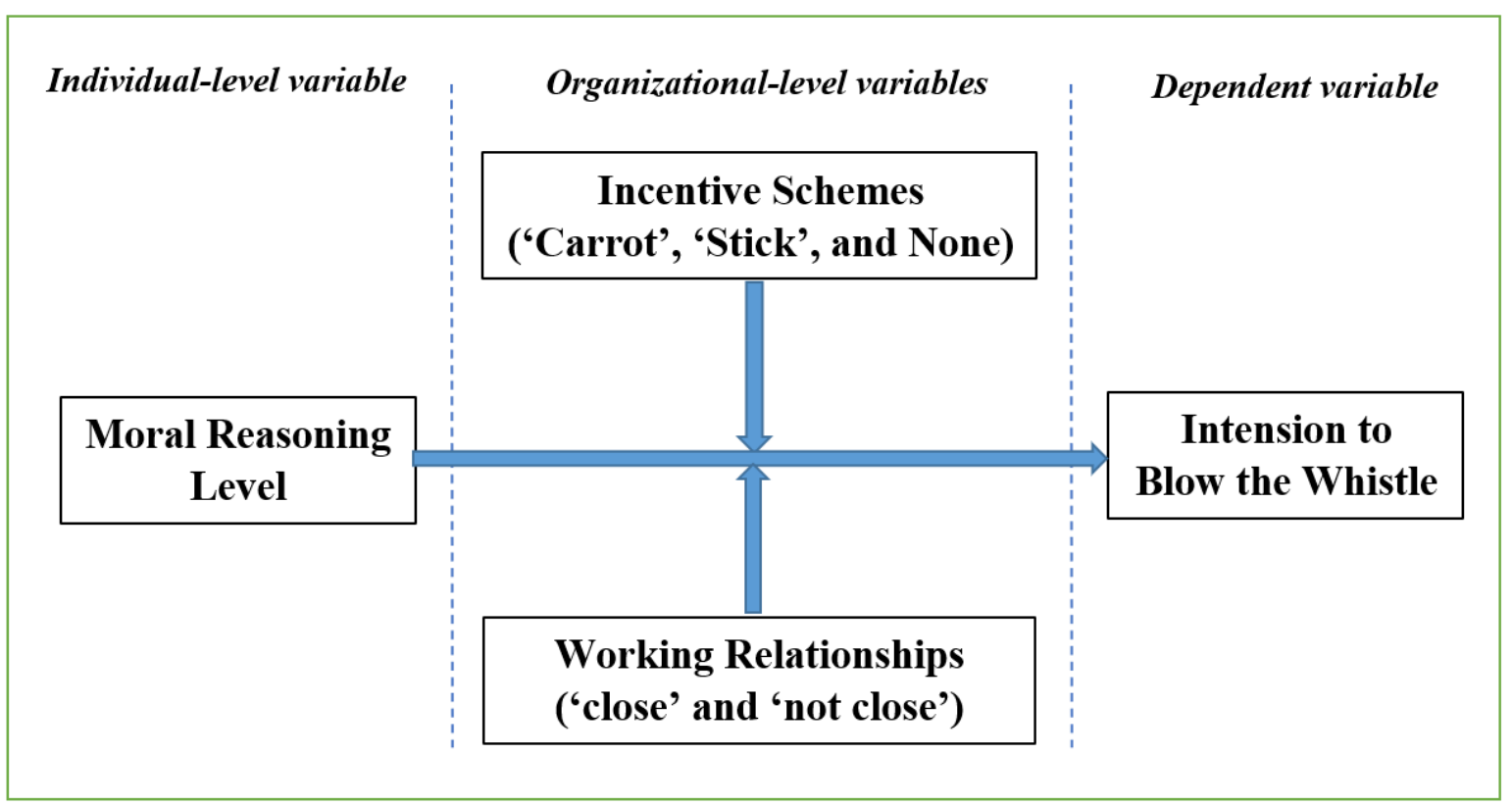

Figure 1. Proposed model of the whistleblowing intention

\section{Methods}

\section{Experiment Design}

This study employed a paper-pencil laboratory experimental method for collecting the data. The experimental design was a $2 \times 3$ factorial design between subjects (see Table 1). The manipulated variables included in- they were chosen based on several considerations. Firstly, graduate students are generally regarded as being more mature in terms of their cognitive stage. It is suggested that most individuals' moral development rarely moves to reach the law and order stage (stages 5 and 6) before reaching their mid-20s (Kohlberg, 1971).

Table 1. Experimental design

\begin{tabular}{llllll}
\hline \multirow{2}{*}{ Moral reasoning stage } & \multirow{2}{*}{ Treatment } & \multicolumn{3}{c}{ Incentive Schemes } \\
\cline { 3 - 5 } & & "Carrot" & "Stick" & No Incentive \\
\cline { 3 - 5 } & \multirow{2}{*}{ Working Relationships } & Close & Scenario C-1 & Scenario C-3 & Scenario C-5 \\
& & Not Close & Scenario C-2 & Scenario C-4 & Scenario C-6 \\
\hline
\end{tabular}

centive schemes (no incentives, rewards "carrot," and punishment "stick") and working relationships (close and not close). The moral reasoning variable was measured using Weber \& McGivern (2010), with the instruments adapted to the Indonesian context.
Second, previous studies suggest that people's moral reasoning tends to deteriorate once they enter the world of work (Dellaportas, 2006, Welton et al., 1994). Thus measuring graduate students' states of morality could be the best option-compared to undergraduate students - as they should have 
developed cognitively over time, progressing to additional moral reasoning levels as they matured and obtained a higher education. Third, among the graduate students, there would be some who have been working and some who might have no working experi- spondents comprised 58 males and 89 females, with $48.30 \%$ having work experience of 3.8 years on average. Out of those who had work experience, $54.93 \%$ had worked as accounting staff, and $42.25 \%$ had other occupations, while two respondents did not

Table 2. Participants' demographics

\begin{tabular}{lc}
\hline Demographic variable & Number of participants \\
\hline Total participants & 179 \\
Fail manipulation checks & 32 \\
Observations used & 147 \\
Male & 58 \\
Female & 89 \\
With previous work experience & $71(54.93 \%$ of them as accounting staff $)$ \\
Without previous work experience & 76 \\
Mean age & 26.42 years \\
\hline
\end{tabular}

ence. Thus, this situation allows a comparison to check any different states of morality between both groups of students without taking another set of respondents from a professional setting.

The participants were invited to participate in the experiment through printed brochures and social media. Hence, they voluntarily took part in the experiment. The experiment was run in two batches, and a total of 179 students participated in the experiment. The first batch involved 107 participants, while the second batch had 72 participants. Upon completing the experiment, they were rewarded with a monetary donation to disaster relief efforts in Indonesia. From the collected responses, 80 from the first batch and 67 from the second batch of participants passed both the internal consistency check for the moral reasoning instrument and the manipulation checks for the treatment; thus, a total of 147 observations could be used for further analysis.

The demographic summary of the respondents is displayed in Table 2. The re- disclose their previous jobs. None of these demographic variables, i.e., gender, work experience, and whistleblowing experience, are significantly associated with the dependent variable. There are no meaningful differences in the results between male and female respondents or between respondents with work experience and those without work experience.

\section{Measurement}

The whistleblowing intention was used as the dependent variable and measured by a continuous scale from 0 to 100 . The independent variables were: (1) moral reasoning stage, (2) incentive schemes, and (3) working relationships. According to Weber \& McGivern (2010), the moral reasoning stage was measured by asking the respondents to rate both the strength and importance of four moral statements (which mirrored the four stages of moral development) in response to an ethical dilemma in a business context. Additionally, composite scores were created for each moral statement to capture the dom- 
inant moral reasoning stage. The other two independent variables, incentive schemes and working relationships, were manipulated using the instrument used by Boo et al., (2016). In alignment with Boo et al., (2016), the presence (or absence) of incentive schemes was further divided into three manipulations of "carrot, stick, and no-incentive." The closeness of the working relationship, in turn, was measured in binary terms (close and not close). Additionally, other control variables were introduced, such as age, gender, and working experience.

\section{Experimental Procedures and Task}

The experiment was done in three stages. In Stage 1, after all the participants were randomly assigned to one of the experimental cells, they were given two scenarios to measure their dominant moral reasoning stage. They were provided with three different ethical dilemma scenarios. The scenarios were adapted from the instrument developed by Weber \& McGivern (2010) from Evelyn and Roger's cases. They were instructed to read and complete the tests in a pre-defined order. In the first scenario, the participants evaluate four statements on a 10-point Likert scale concerning the strength of their beliefs for each statement. Afterward, they were requested to rate the importance of their beliefs on each of the statements using a 5-point Likert scale. This procedure was repeated in the second scenario. For both scenarios, they had 10 minutes to finish each one.

The second stage employed the treatment instrument adapted from the vignette used in Boo et al., (2016). The participants were given an audit assignment scenario, by a large public accounting firm, of the DEF public company's financial statements, one of the accounting firm's primary clients with material audit fees. In the vignette, the audit manager finds misstatements that materially overstate company DEF's earnings and profits. The client company does this to book or recognize significant sales transaction revenues prematurely, because their new goods' delivery occurs after the balance sheet's date. However, the DEF company CEO has succeeded in persuading the partner auditor, the audit engagement holder, not to insist on correcting the misstatement of income. Because if there is a correction, it will be very detrimental to DEF, in the form of violations of its bank loan agreements and missing the analyst's consensus forecast. The audit manager believes that, based on the evidence, sales have not been ordered in the financial reporting period, so he approaches the partner auditor to voice his concerns. Although the audit manager continued to be concerned, the partner auditor insisted on allowing DEF to acknowledge sales before the end of the year, so no adjustments were needed.

The participants were informed that the public accounting firm has a reporting hotline. The staff members could report any wrongdoing, any lack of integrity, or questionable behavior anonymously through an online reporting hotline available at any time ( 24 hours a day and seven days a week). The reporting system will regulate the reporter's confidentiality by providing a password and immediately requiring the reporter to change that password with a personal password. The reporter can maintain two-way communication with the company while ensuring their anonymity. The accounting firm uses this reporting hotline service from an independent and reputable ethics hotline service provider. All reports will be treated as highly confidential, and all reported cases will be seriously considered and promptly followed up. The company will protect the staff member who 
makes a report from any form of retaliation.

After reading the case scenario, the participants were asked to assess an auditor's tendency in situations such as those faced by the audit manager to report any wrongdoing, on a scale ranging from 0 percent (clearly not reporting) to 100 percent (certainty reporting). The next question was whether he/she would report it by ticking the answer option "yes" or "no." The participants were also asked to explain the reasons for their assessment briefly.

In the last stage, the participants were asked to complete a debriefing questionnaire consisting of demographic data questions and a manipulation check. Each item of experimental material for these three stages was distributed to participants in three envelopes stamped A, B, and C, according to the material stages. In the beginning, the participants were instructed to complete the material sequentially, starting from A, B, and C. The participants may open envelope B only after they have completed and put envelope A's material into envelope A. Likewise, envelope $C$ can only be opened after they finish and insert envelope B's material into envelope B. The scenario in envelope $C$, in turn, was divided into six different stories, which contained a combination of incentive schemes and working relationships. Four of the stories were randomly distributed to the participants in the treatment group. The remaining two stories, which contained no information about incentive schemes, were distributed to the control group (Boo et al., 2016).

After completing the first two stages, the participants were randomly assigned to six experimental cells and given various scenarios in envelope $C$. The participants were asked to assess the likelihood of them blowing the whistle on the perpetrator, based on the situation and conditions stated in the scenario, on a continuous scale ranging from 0 percent (definitely not report) to 100 percent (definitely report). Also, the participants were required to explain the reason for their decision briefly. The allocated time for this third stage was 15 minutes. Finally, 10 minutes were spent completing the debriefing questionnaire. The experiment needed around 45 minutes to complete all the tasks.

\section{Results}

\section{Manipulation Checks}

Manipulation checks were used to test the treatment of the working relationship and incentive schemes variables. For the working relationship variable, the participants were asked to assess the working relationship between the audit manager and the audit partner before the current audit assignment, using a scale ranging from 1 (not close) to 5 (very close). The results showed that, as expected, the participants in the "close" treatment rated it as a significantly closer working relationship than those in the "not close" treatment did, with an average score of 4.86 and 2.07, respectively, with a one-tail p-value of 0.001 .

For the incentive scheme's manipulation, the participants were asked to answer two questions. The first question was whether the public accounting firm had a policy that employees who fail to report any wrongdoing by other employees would be subject to sanctions by the company, including being terminated. The second question was whether the public accounting firm had a policy that employees who report any wrongdoing by other employees would be rewarded by the company, including promotion to a higher position. Thirty-two participants answered the first, second, or both questions incorrect- 
Gadjah Mada International Journal of Business - September-December, Vol. 23, No. 3, 2021

ly and were excluded from the subsequent analysis.

\section{Hypotheses Tests}

Table 3 Panel A shows that the participants converged into two dominant moral reasoning stages. Participants in Stage 3 | 4 (n $=93$ ) showed a mean propensity to blow the whistle of 83.98 , with a standard deviation of 13.64. Whereas participants in Stage $5 \mid 6(n$ $=54$ ) showed a mean propensity to blow the whistle of 90.29 , with a standard deviation of 12.02 . The mean propensity to blow the whistle of Stage 3 | 4 was significantly lower than Stage $5 \mid 6$, at a p-value of 0.024 with a $\mathrm{t}$-value of 2.68. This figure indicated that the moral reasoning stage had positive effects on the propensity to blow the whistle.

Table 3 Panel B shows the mean and standard deviation for the propensity to blow the whistle based on incentive schemes and the working relationship. From the means alone, it appears that the working relationship and incentive scheme consistently reduced the propensity to blow the whistle, with means of 89.09 (12.40) vs. 82.75 (13.67) for a not close vs. a close working relationship and of 82.33 (12.64) vs. 84.62 (11.73) vs. 81.47 (16.13) for no incentive vs. carrot vs. stick incentive schemes. To figure out whether any of these differences were statistically significant, a three-way ANOVA was performed. Table 3 Panel $C$ presents the results.

$\mathrm{H}_{1}$ posits that the higher the dominant stage of an individual's moral reasoning is, the more likely he/she is to blow the whistle. As shown in Table 3 Panel C, the moral reasoning stage is statistically significant $(\mathrm{F}=$ 9.27; $\mathrm{p}=0.001)$, producing the difference in the propensity to blow the whistle, thus supporting $\mathrm{H}_{1}$. The mean propensity to blow the whistle of moral reasoning Stage 5 | 6 (90.29) is positive and significantly higher than Stage 3 | 4 (83.98), at a p-value of 0.024

$\mathrm{H}_{2}$, in turn, predicts that a close working relationship will lower the likelihood of blowing the whistle. The result in Table 3 Panel C shows that the working relationship's main effect significantly affects the propensity to blow the whistle $(\mathrm{F}=4.33$; $\mathrm{p}=0.041)$. The mean propensity to blow the whistle of close relationships is 82.74 (13.67), which is significantly lower than that of not close relationships, which is 89.09 (12.40) at a p-value of 0.046 .

$\mathrm{H}_{3}$ projects that individuals exposed to incentive schemes will show a higher probability of blowing the whistle than those without an incentive scheme. In this respect, the main effects of incentive schemes are marginally significant $(\mathrm{F}=3.64$ and $\mathrm{p}=0.069)$; thus, support is found for the hypothesis. The mean propensity to blow the whistle of the carrot incentive is the highest, compared to the stick incentive and no-incentive, which are 89.24 (11.12), 84.46 (15.52), and 83.41 (12.23), respectively, at a $\mathrm{p}$-value $=0.017$.

Lastly, $\mathrm{H}_{4}$ states that individuals with higher moral reasoning stages will find their likelihood of blowing the whistle less affected by working relationships and incentive schemes. No support is found for the interaction between the moral reasoning stage, the working relationship, and incentive schemes $(F=1.46$ and $p=0.401)$. Similarly, the interaction between moral reasoning and incentive schemes does not play a significant role $(F=1.81$ and $p=0.147)$. No significance is found for the interaction between a working relationship and incentive schemes $(\mathrm{F}=1.41$ and $\mathrm{p}=0.344)$. However, the interaction between a working relationship and incentive schemes is marginally significant, with $\mathrm{F}=$ 3.33 and $p=0.079$. 
Table 3. Effects of Moral Reasoning, Incentive Schemes, and Working Relationships on Propensity to Blow the Whistle

Panel A. Descriptive statistics (mean and standard deviation) of the effects of moral reasoning on the propensity to blow the whistle

\begin{tabular}{llcc}
\hline \multirow{2}{*}{ Moral reasoning stage } & \multicolumn{2}{c}{ The propensity to blow the whistle } \\
\cline { 2 - 4 } & Mean & Std. Dev. & Frequency \\
\hline Stage 3 | 4 & 83.98 & 13.64 & 53 \\
Stage 5 | 6 & 90.29 & 12.02 & 54 \\
Stage 3 $\mid$ 4 vs Stage 5 & 6 & & t-value $=2.68$ and p-value $=0.024$ \\
\hline
\end{tabular}

Panel B. Descriptive statistics (mean and standard deviation) of the effects of incentive scheme and working relationship on the propensity to blow the whistle

\begin{tabular}{lcccc}
\hline \multirow{2}{*}{ Working relationship } & \multicolumn{4}{c}{ Incentive scheme } \\
\cline { 2 - 5 } Not Close & No incentive & Carrot approach & Stick approach & Total \\
& 84.73 & 93.06 & 87.68 & 89.09 \\
& $(11.72)$ & $(10.61)$ & $(14.86)$ & $(12.40)$ \\
Close & $\mathrm{n}=18$ & $\mathrm{n}=29$ & $\mathrm{n}=26$ & $\mathrm{n}=73$ \\
& 82.33 & 84.62 & 81.47 & 82.75 \\
Total & $(12.64)$ & $(11.73)$ & $(16.13)$ & $(13.67)$ \\
& $\mathrm{n}=22$ & $\mathrm{n}=24$ & $\mathrm{n}=28$ & $\mathrm{n}=74$ \\
& 83.41 & 89.24 & 84.46 & 86.30 \\
& $(12.23)$ & $(11.12)$ & $(15.52)$ & $(13.04)$ \\
& $\mathrm{n}=40$ & $\mathrm{n}=53$ & $\mathrm{n}=54$ & $\mathrm{~N}=147$ \\
\hline
\end{tabular}

Panel C. Analysis of variance on the propensity to blow the whistle by moral reasoning stage, incentive schemes, and working relationships

\begin{tabular}{llll}
\hline Source & Df & F & p \\
\hline Moral reasoning stage & 1 & 9.27 & $0.001^{*}$ \\
Working relationships & 1 & 4.33 & $0.041^{* *}$ \\
Incentive schemes & 2 & 3.64 & $0.069^{* * *}$ \\
Moral reasoning stage's working relationships & 2 & 3.54 & $0.035^{* *}$ \\
Moral reasoning stage's incentive schemes & 3 & 1.81 & 0.147 \\
Working relationships' incentive schemes & 2 & 1.41 & 0.344 \\
Moral reasoning stage $\times$ working relationships $\times$ incen- & 2 & 1.46 & 0.401 \\
tive schemes & & \\
${ }^{*}=$ significant at $\mathrm{p}<0.00 ;{ }^{* *}=$ significant at $\mathrm{p}<0.05 ;{ }^{* * *}=$ significant at $\mathrm{p}<0.10$ &
\end{tabular}

\section{Discussion}

This study found that the moral reasoning stage played a significant role in increasing the participants' tendency to blow the whistle when facing any wrongdoing in their company. These results are consistent with the findings of previous studies (Cheng et al.,
2019; Dungan et al., 2019; Doe et al., 2020; May-Amy et al., 2020; Latan et al., 2018; and Latan et al., 2020). Individuals with a higher level of moral reasoning have a better ability to analyze ethical dilemmas and also have a higher desire to report fraud than individuals with a lower level of moral reasoning 
(Weber \& McGivern, 2010; Liyanarachchi \& Newdick, 2009; Near \& Miceli, 2005; and Gundlach et al., 2003). These findings are also consistent with the theory of moral reasoning, as documented by Rest (1983), which stated that moral behavior refers to and uses a moral guideline to regulate cooperation between humans in realizing responsibilities, rights, and benefits.

Similarly, the working relationships significantly affected the participants' tendency to blow the whistle; the working relationship's closeness reduced the participants' probability of reporting any wrongdoing by their colleagues. The results are consistent with the results of the studies by Boo et al., (2016), Latan et al., (2018), and Xu Ziegenfuss (2008), who all used the subject of public accountants, and the conclusion of the study by Wang et al., (2018), Chang et al., (2017) and Rehg et al., (2008) with the subject of non-accountant managers. However, this study's results contradict the study results by Adkins et al., (1996) and Werbel \& Johnson (2001) when the interaction between colleagues in the team is very intense. In this condition, the working relationship's closeness can increase the tendency to report any wrongdoing because their work relationship has been very comfortable, and good synergy is achieved through their common goals.

The test of the incentive scheme's effects (no-incentives, carrots, and sticks) on individuals' tendency to blow the whistle is only marginally supported. In general, these results are consistent with the results of research by Latan et al., (2019b), Andon et al., (2018), Rose et al., (2018), Boo et al., (2016), Pope \& Lee (2013); Brink et al., (2013); and $\mathrm{Xu} \&$ Ziegenfuss (2008), who all found that incentive schemes can increase employees' tendencies to blow the whistle. However, this study's marginal support may be because the participants have different perceptions of the value between reward and punishment incentive schemes (Boo et al., 2016). It is consistent with the results of a detailed analysis of incentive schemes' impacts on the propensity to blow the whistle. The mean difference in the propensity to blow the whistle in the carrot cell was significantly higher than that in the stick and no-incentives cells, at $\mathrm{p}=0.034$. Simultaneously, the means for the stick and no-incentives cells were not statistically different at $\mathrm{p}=0.174$.

However, this study's results do not provide sufficient evidence to support the moral reasoning stage's role in strengthening individuals' tendencies to blow the whistle when they find any wrongdoing. Although the interaction between the working relationship and moral reasoning still had a significant effect on individuals' tendencies to blow the whistle $(\mathrm{F}=3.54$ and $\mathrm{p}=0.035)$, the existence of an incentive scheme reduced the robustness of these results. Therefore, the interaction effect of moral reasoning, working relationships, and incentive schemes did not increase an individual's likelihood of blowing the whistle.

The alternative perspective of why the findings did not support the interaction effect may be caused by the types of "carrot vs. stick" incentives, which could be interpreted as opposites. As a result, the close working relationship's negative effect was reduced (Wang et al., 2018). Also, a combination of "carrot and stick" incentive schemes can reduce the working relationship's moderating effect on the tendency to blow the whistle (Trompeter et al., 2014). Another plausible reason for the lack of support was discussed by Boo et al., (2016), in which they argued that "carrot" may impede the propensity to blow 
the whistle as it can be perceived as harming others for personal gain. Hence there is a canceling effect between the "carrot" incentive scheme and a close working relationship.

\section{Conclusion}

This study examined whether moral reasoning plays a significant role in strengthening the effects of the working relationship and incentive schemes on the tendency for whistleblowing when individuals find any wrongdoing by their colleagues. Consistent with previous studies by Weber and McGivern (2010), Boo et al., (2016), Latan et al., (2018), Pope and Lee (2013), and Brink et al., (2013), this study indicates that the simple effect of moral reasoning or a close working relationship is significant, while an incentive scheme is marginally significant for increasing the propensity to blow the whistle. Similarly, the combination of moral reasoning and the working relationship significantly improves the tendency to blow the whistle. However, the combined effects of moral reasoning vs. the working relationship and moral reasoning vs. the working relationship vs. incentive scheme fail to increase the tendency to blow the whistle.

Finally, the moral reasoning stage's role in increasing the participants' tendencies to report wrongdoers is less robust. When a close working relationship between the participants is presented, moral reasoning is still quite robust; however, this role is lost in both conditions when the incentive scheme is included and when the incentive scheme and working relationship are included. It is indi- cated that the lack of robustness for the role of moral reasoning is probably due to the nature of the incentive scheme, which can be interpreted as a contradiction between reward and punishment, or the working relationship between individuals who are too close and intimate. Therefore, further research is necessary to consider a more controlled method of manipulating work relationships and incentive schemes.

\section{Limitations}

Several limitations are pertinent to this study. First, the experimental study relies solely on the textual scenarios. They may not capture the workplace's complex reality and the social interactions embedded in it. Second, few conclusions can be made about the action of whistleblowing itself. Whistleblowing is comprised of a long strand of processes, and the conclusions reached in this study should be taken with caution. Third, this study uses accounting graduate students as its participants. Although no difference in the results was found between those with and without work experience, it will be necessary to research with practicing auditors or accountants since they experience the daily pressures to comply with the organization's norms and methods of working . Fourth, other individual-level attributes that are found to influence the whistleblowing intention were not captured and measured in this study, such as personal orientation (Park et al., 2014) and the personal cost of reporting (Latan et al., 2018; Latan et al., 2019b; and Schultz et al., 1993) 
Gadjah Mada International Journal of Business - September-December, Vol. 23, No. 3, 2021

\section{References}

Adkins, C. L., Ravlin, E. C., \& Meglino, B. M. (1996). Value congruence between co-workers and its relationship to work outcomes. Group \& Organization Management, 21(4), 439-460.

Alleyne, P., Hudaib, M., \& Haniffa, R. (2018). The moderating role of perceived organizational support in breaking the silence of public accountants. Journal of Business Ethics, 147 (3), 509-527.

Alleyne, P., Hudaib, M., \& Pike, R. (2013). Towards a conceptual model of whistle $\square$ blowing intentions among external auditors. The British Accounting Review, 45(1), 10-23.

Andon, P., Free, C., Jidin, R., Monroe, G. S., \& Turner, M. J. (2018). The Impact of Financial Incentives and Perceptions of Seriousness on Whistleblowing Intention. Journal of Business Ethics, 151(1), 165-178. doi: 10.1007/s10551-016.

Ariely, D., Bracha, A., \& Meier, S. (2009). Doing Good or Doing Well? Image Motivation and Monetary Incentives in Behaving Prosocially. American Economic Review, 99(1), 544-55.

Arnold, D. F., \& Ponemon, L. A. (1991). Internal Auditors Perceptions of Whistle Blowing and the Influence of Moral Reasoning: An Experiment. Auditing: A Journal of Practice and Theory 10, 1-15.

Arvey, R. D., \& Ivancevich., J. M. (1980). Punishment in organizations: A review, propositions, and research suggestions. Academy of Management Review, 5 (1): 123-132.

Baker, G. P., Jensen, M. C., \& Murphy, K. J. (1998). Compensation and Incentives: Practice vs. Theory. The Journal of Finance, July, Vol. 43, No. 3, 593-616.

Batson, C. D., \& Powell, A. A. (2003). 'Altruism and Prosocial Behavior', in Millon, T. \& Lerner, M.J. (eds.). Handbook of Psychology. Hoboken: John Wiley \& Sons, 463-484.

Bénabou, R., \& Tirole, J. (2006). Incentives and Prosocial Behavior. The American Economic Review, 96(5), 1652-1678.

Boo, E. F., Ng, T. B.-P., \& Shankar, P. G. (2016). Effects of Incentive Scheme and Working Relationship on Whistle-Blowing in an Audit Setting. AUDITING: A Journal of Practice \& Theory, 35(4), 23-38.

Brief, A. P., \& Motowidlo, S. J. (1986). Prosocial organizational behaviors. Academy of Management Review, 11(4), 710-725.

Brink, A. G., Lowe, D. J., \& Victoravich, L. M. (2013). The effect of evidence strength and internal rewards on intentions to report fraud in the Dodd-Frank regulatory environment. Auditing: A Journal of Practice \& Theory 32 (3):; 87-104.

Brooks, R. (2018). The financial scandal no one is talking about. The Guardian. Available at: https:// www.theguardian.com/ news/2018/may/29/ the-financial-scandal-no-one-is-talking-aboutbig-four-accountancy-firms.

Ceva, E., \& Bocchiola, M. (2018). Personal trust, public accountability, and the justification of whistleblowing. Journal of Political Philosophy, 27(2), 187-206.

Chan, S. Y., \& Leung, P. (2006). The Effects of Accounting Students Ethical Reasoning and Personal Factors on Their Ethical Sensitivity. Managerial Auditing Journal 21, 436-457.

Chang, Y., Wilding, M., \& Shin, M. C. (2017). Determinants of whistleblowing intention: evidence from the South Korean government. Public Performance \& Management Review, 40(4), 676-700. 
Cheng, J., Bai, H., \& Yang, X. (2019). Ethical Leadership and Internal Whistleblowing: A Mediated Moderation Model. Journal of Business Ethics, 155(1), 115-130. doi: 10.1007/s10551017-3517-3.

Cortina, L. M., \& Magley, V. J. (2003). Raising voice, risking retaliation: Events following interpersonal mistreatment in the workplace. Journal of Occupational Health Psychology, 8(4), 247-265.

Davis, M. (1996). Some paradoxes of whistleblowing. Business and Professional Ethics Journal. 15(1), 3-19.

Deci, E. (1972). The Effects of Contingent and Non-contingent Rewards and Controls on Intrinsic Motivation. Organizational Behavior and Human Performance 8, 51-74.

Dellaportas, S. (2006). Making a difference with a discrete course on accounting ethics',. Journal of Business Ethics, 65(4), 391-404.

Delmas, C. (2015). The ethics of government whistleblowing. Social Theory and Practice, 41, 77105.

Doe, R., Landrum, B. B., Barclay, E. J., \& Carona, K. M. (2020). Normative Motivation in Whistleblowing Decision Making. Journal of organizational psychology, 20(4), 23-29.

Dozier, J. B., \& Miceli, M. P. (1985). Potential Predictors of Whistle Blowing: A Prosocial Behaviour Perspective. Academy of Management Review 10, 823-836.

Dungan, J. A., Young, L., \& Waytz, A. (2019). The power of moral concerns in predicting whistleblowing decisions. Journal of Experimental Social Psychology. 85, 1-12 Doi: 10.1016/j. jesp.2019.103848.

Eisenberg, N., \& Miller, P. A. (1987). The relation of empathy to prosocial and related behaviors. Psychological Bulletin, 101(1), 91-119.

Erkmen, T., Esen, E., \& Özsözgün Çalışkan, A. (2014). An empirical research about whistleblowing behavior in accounting context. Journal of Accounting \& Organizational Change, 10(2), 229-243.

Fieger, P., \& Rice, B. S. (2018). Whistle-blowing in the Australian Public Service: The role of employee ethnicity and occupational affiliation. Personnel Review, 47(3), 613-629.

Gundlach, M. J., Douglas, S. C., \& Martinko, M. J. (2003). The Decisionto Blowthe Whistle: A Social Information Processing Framework. Academy of Management Review 28(1), 107-123.

Hamner, W. C. (1975). How to Ruin Motivation with Pay. Compensation Review 7, 17-27.

Jackson, D., Peters, K., Andrew, S., Edenborough, M., Halcomb, E., Luck, L., . . . Weaver, R. (2010). Trial and retribution: A qualitative study of whistleblowing and workplace relationships in nursing. Contemporary Nurse, 36(1-2), 34-44.

Kohlberg, L. (1971). Stages of moral development as a basis for moral education', in Beck, C.M., Crittenden, B.S. \& Sullivan, E.V. (eds.) Moral Education: Interdisciplinary Approaches. New York: Newman Press.

Kohlberg, L., \& Hersh, R. H. (1977). Moral Development: A Review of the Theory. Theory Into Practice, 16(2), 53-59.

Kohn, A. (1988). Incentives Can be Bad for Business. INC, 93-94.

Latan, H., Chiappetta Jabbour, C. J., \& Lopes de Sousa Jabbour, A. B. (2019a). Ethical Awareness, Ethical Judgment and Whistleblowing: A Moderated Mediation Analysis. ournal of Business Ethics, 155(1), 289-304. doi: 10.1007/s10551-017-3534-2. 
Gadjah Mada International Journal of Business - September-December, Vol. 23, No. 3, 2021

Latan, H., Chiappetta Jabbour, C. J., \& Lopes de Sousa Jabbour, A. B. (2019b). Whistleblowing Triangle': Framework and Empirical Evidence. Journal of Business Ethics, 160(1), 189-204. doi: 10.1007/s10551-018-3862-x.

Latan, H., Ringle, C. M., \& Jabbour, C. J. (2018). Whistleblowing intentions among public accountants in Indonesia: Testing for the moderation effects. Journal of Business Ethics, 152(2), 573-588.

Lee, G., Pittroff, E., \& Turner, M. J. (2018). Is a Uniform Approach to Whistle-Blowing Regulation Effective? Evidence from the United States and Germany. Journal of Business Ethics.

Liyanarachchi, G., \& Newdick, C. (2009). The Impact of Moral Reasoning and Retaliation on Whistle-Blowing: New Zealand Evidence',. Journal of Business Ethics, 89(1), 37-57.

May-Amy, Y. C., Han-Rashwin, L. Y., \& Carter, S. (2020). Antecedents of company secretaries' behaviour and their relationship and effect on intended whistleblowing. Corporate governance (Bradford), 20(5), 837-861. doi: 10.1108/CG-10-2019-0308.

Mesmer-Magnus, J. R., \& Viswesvaran, C. (2005). Whistleblowing in organizations: An examination of correlates of whistleblowing intentions, actions, and retaliation. Journal of Business Ethics, 62(3), 277-297.

Miceli, M. P. (2004). Whistle-Blowing Research and the Insider: Lessons Learned and Yet to be Learned. Journal of Management Inquiry 13, 364-366.

Miceli, M. P., \& Near, J. P. (1985). Characteristics of organizational climate and perceived wrongdoing associated with whistle $\square$ blowing decisions. Personnel Psychology, 38(3), 525-544.

Miceli, M. P., \& Near, J. P. (1992). Blowing the whistle: The organizational and legal implications for companies and employees. New York: Lexington Books.

Miceli, M. P., Near, J. P., \& Dworkin, T. M. (2008). Whistle-blowing in organizations. New York: Routledge.

Milliken, F. J., Morrison, E. W., \& Hewlin, P. F. (2003). An Exploratory Study of Employee Silence: Issues that Employees Don't Communicate Upward and Why. Journal of Management Studies, 40(6), 1453-1476.

Near, J. P., \& Miceli, M. P. (1995). Effective-whistle blowing. Academy of Management Review, 20(3), 679-708.

Near, J. P., \& Miceli, M. P. (2005). Standing Up or Standing By: What Predicts Blowing the Whistle on Organizational Wrongdoing. Research in Personnel and Human Resource Management 24, University of Illinois, USA.

Pangestu, F., \& Rahajeng, D. K. (2020). The Effect of Power Distance, Moral Intensity, and Professional Commitment on Whistleblowing Decisions. Journal of Indonesian economy and business, 35(2), 144-162. doi: 10.22146/jieb.55010.

Park, H., Blenkinsopp, J., \& Park, M. (2014). The influence of an observer's value orientation and personality type on attitudes toward whistleblowing. Journal of Business Ethics, 120(1), 121-129.

Pope, K. R., \& Lee, C. (2013). Could the Dodd Frank Wall Street Reform and Consumer Protection Act of 2010 be helpful in reforming corporate America? An investigation on financial bounties and whistle-blowing behaviors in the private sector. Journal of Business Ethics 112 (4): , 597-607.

Rehg, M. T., Miceli, M. P., \& Van Scotter, J. R. (2008). Antecedents and outcomes of retaliation 
Supriyadi and Prasetyaningsib

against whistleblowers: Gender differences and power relationships. Organization Science, 19(2), 221-240.

Rest, J. (1979). Development in Judging Moral Issues. Minneapolis: University of Minnesota Press.

Rest, J. (1983). 'Morality', in P. H. Mussen (ed.). Handbook of Child Psychology (Vol. III edited by J. Flavell and E. Markman) (Wiley, New York).

Rest, J., Narvaez, D., Bebeau, M. J., \& Thoma, S. (1999). Postconventional Moral Thinking: A Neo-Kohlbergian Approach. Mahwah: Lawrence Erlbaum Associates.

Rocha, E., \& Kleiner, B. H. (2005). To Blow or Not to Blow the Whistle? That is the Question. Management Research News 28(11/12), 80-87.

Rose, J. M., Brink, A. G., \& Norman, C. S. (2018). The Effects of Compensation Structures and Monetary Rewards on Managers' Decisions to Blow the Whistle. Journal of Business Ethics, 150(3), 853-862. doi: 10.1007/s10551-016-3222-7.

Schultz, J. J., Johnson, D. A., Morris, D., \& Dyrnes, S. (1993). An investigation of the reporting of questionable acts in an international setting. Journal of Accounting Research, 75-103.

Schwartz, M. S. (2016). Ethical Decision-Making Theory: An Integrated Approach. Journal of Business Ethics, 139:, 755-776.

Silverman, K., Jarvis, B. P., Jessel, J., \& Lopez, A. A. (2016). Incentives and motivation. Transl Issues Psychol Sci. 2016; 2(2):. 97-100.

Singh, J. B. (2011). Determinants of the effectiveness of corporate codes of ethics: An empirical study. Journal of Business Ethics, 101(3), 385-395.

Skivenes, M., \& Trygstad, S. C. (2010). When whistle-blowing works: The Norwegian case. Human Relations, 63(7), 1071-1097.

Taylor, E. Z., \& Curtis, M. B. (2010). An examination of the layers of workplace influences in ethical judgments: Whistleblowing likelihood and perseverance in public accounting. Journal of Business Ethics, 93(1), 21-37.

The-Jakarta-Post. (2018a). Consumer finance firm allegedly defrauds banks of Rp 14 trillion',. The Jakarta Post. Available at: http:// www.thejakartapost.com/news/2018/09/25/-consumer-finance-firm-allegedly-defrauds-banks-of-rp-14-trillion.html.

The-Jakarta-Post. (2018b). Doubts over audited reports. The Jakarta Post. Available at: http:/ / mmw. thejakartapost.com/academia/2018/06/04/doubts-over-audited-reports.html.

Trompeter, G. M., Carpenter, T. D., Jones, K. L., \& Riley Jr., R. A. (2014). Insights for research and practice: What we learn about fraud from other disciplines. Accounting Horizons 28 (4), 769-804.

Tsui, J. S. (1996). Auditors' ethical reasoning: Some audit conflict and cross cultural evidence. The International Journal of Accounting, 31(1), 121-133.

Uddin, N., \& Gillett, P. R. (2002). The Effects of Moral Reasoning and Self-Monitoring on CFO Intention to Report Fraudulently on Financial Statements. Accounting Organizations and Society 40(1), 41-51.

Verschoor, C. (2005). Is This the Age of Whistleblowers? Strategic Finance 86(7), 17-18.

Wang, T. K., Fu, K.-J., \& Yang, K. (2018). Do Good Workplace Relationships Encourage Employee Whistle-Blowing? Public Performance \& Management Review, Vol. 41, No. 4, 768-789.

Weber, J. (1991). Adapting Kohlberg to enhance the assessment of managers' moral reasoning. Business Ethics Quarterly, 1(3), 293-318. 
Gadjah Mada International Journal of Business - September-December, Vol. 23, No. 3, 2021

Weber, J., \& McGivern, E. (2010). A New Methodological Approach for Studying Moral Reasoning among Managers in Business Settings. Journal of Business Ethics, 92(1), 149-166.

Welton, R. E., Lagrone, R. M., \& Davis, J. R. (1994). Promoting the moral development of accounting graduate students: an instructional design and assessment. Accounting Education, $3(1), 35-50$.

Werbel, J. D., \& Johnson, D. J. (2001). The use of person-group fit for employment selection: A missing link in person-environment fit. Human Resource Management, 40(3), 227-240.

Xu, Y., \& Ziegenfuss, D. E. (2008). Reward Systems, Moral Reasoning, and Internal Auditors' Reporting Wrongdoing. Journal of Business and Psychology, 22(4), 323-331.

Zollo, L., Pellegrini, M. M., \& Ciappei, C. (2017). What Sparks Ethical Decision Making? The Interplay Between Moral Intuition and Moral Reasoning: Lessons from the Scholastic Doctrine. Journal of Business Ethics, 145,, 681-700. 